\title{
High CAMP levels antagonize the reprogramming of gene expression that occurs at the diauxic shift in Saccharomyces cerevisiae
}

\author{
Emmanuelle Boy-Marcotte, ${ }^{1}$ Djamila Tadi, ${ }^{1}$ Michel Perrot, ${ }^{2}$ \\ Helian Boucherie ${ }^{2}$ and Michel Jacquet ${ }^{1}$
}

\begin{abstract}
Author for correspondence: Emmanuelle Boy-Marcotte. Tel: +33 1 69416511. Fax: +33 169417296. e-mail: BOY@igmors.u-psud.Fr
\end{abstract}

1 Institut de Génétique et Microbiologie, URA CNRS D1354, Université Paris XI, Bátiment 400, 91405 Orsay Cedex, France

2 Laboratoire de Génétique, UPR CNRS 9026, Avenue des Facultés, 33405 Talence Cedex, France

\begin{abstract}
In order to analyse the involvement of the CAMP pathway in the regulation of gene expression in Saccharomyces cerevisiae, we have examined the effect of CAMP on protein synthesis by using two-dimensional gel electrophoresis. CAMP had only a minor effect on the protein pattern of cells growing exponentially on glucose. However, it interfered with the changes in gene expression normally occurring upon glucose exhaustion in yeast cultures, maintaining a protein pattern typical of cells growing on glucose. This effect was accompanied by a delay before growth recovery on ethanol. We propose a model in which the CAMP-signalling pathway has a role in the maintenance of gene expression, rather than in the determination of a specific programme. A decrease of CAMP would then be required for metabolic transitions such as the diauxic phase.
\end{abstract}

Keywords: gene regulation, cAMP-dependent protein kinase (PKA) effects, cAMP pathway

\section{INTRODUCTION}

In the yeast Saccharomyces cerevisiae, the cAMP-signalling pathway is involved in a wide variety of cellular processes and interferes with the cell's response to environmental variations, as deduced from the study of mutants altered in this pathway. cAMP is required for normal cell growth; its absence blocks cell division in early $G_{1}$ phase. In the absence of the regulatory subunit (Bcylp) or in the excess of cAMP, a high level of constitutive cAMP-dependent protein kinase (PKA) activity allows growth and division but is lethal to cells subjected to heat-shock or nitrogen starvation. It prevents the accumulation of trehalose and glycogen. In addition, sporulation is blocked but pseudohyphal growth is facilitated (Boy-Marcotte et al., 1987; Gimeno et al., 1992; Kataoka et al., 1984; Matsumoto et al., 1985; Tatchell, 1993; Toda et al., 1985).

Although the components of this pathway are well known (for a review, see Tatchell, 1993), its activation and the nature of the regulatory signals are not clearly understood. The only known signals which activate this pathway are the rapidly fermentable sugars such as glucose, fructose

Abbreviations: PKA, CAMP-dependent protein kinase; 2-D, twodimensional. and mannose (Van Aelst et al., 1990). Two- to threefold variations of the cAMP intracellular concentration have been reported, depending on the carbon source (François et al., 1987; Russel et al., 1993) and on the cell division cycle (Watson \& Berry, 1977). It is not yet understood how this pathway controls such a large number of cellular processes, since very few direct targets of the PKA have been identified to date (Van Der Plaat, 1974; François et al., 1984; Thevelein, 1984; Kinney \& Carman, 1988; Cherry et al., 1989).

It has been shown in mammalian cells that when PKA is activated by cAMP, the catalytic subunit moves to the nucleus (Adams et al., 1991). In mammalian cells, cAMPdependent transcriptional regulation occurs through cAMP-response elements (CREs), which are binding sites for CRE-binding factors (CREBs). Phosphorylation by PKA and dephosphorylation seem to be important mechanisms in the regulation of CREB activity (Brindle \& Montminy, 1992). In S. cerevisiae, negative effects of cAMP have been reported for numerous genes, including ADH2, CTT1, GAC1, GPH1, GSY2, IME2 and UBI4 (Denis et al., 1992; François et al., 1992; Hardy et al., 1994; Marchler et al., 1993; Tanaka et al., 1988) and genes induced by heat-shock, such as HSC82, HSP26, HSP 104, $S S A 1$ and $S S A 3$ (Boorstein \& Craig, 1990; Engelberg et 
al., 1994b). It has been shown that the negative effect of cAMP on the heat-shock response does not involve the heat-shock factor. For $C T T 1$ and $S S A 3$, a similar DNAresponsive element, sensitive to cAMP, has been identified upstream of the $U B I 4$ and $G A C 1$ genes. Nevertheless, no transcriptional regulators have yet been identified which could be responsible for this negative effect of cAMP. Positive regulation by cAMP has also been reported recently for transcription of ribosomal proteins. In this case, the positive effect is mediated by the transcriptional activator RAP1 (Klein \& Struhl, 1994). A positive effect of cAMP on transcription mediated by GCN4 has also been reported (Engelberg et al., 1994a).

In order to better define the role of cAMP on gene expression in glucose-grown cells, we have compared the protein synthesized in cells grown with and without added cAMP by incorporation of $\left[{ }^{35} \mathrm{~S}\right]$ methionine and protein separation by two-dimensional (2-D) gel electrophoresis. This approach has been fruitfully applied to determine several sets of co-regulated genes in S. cerevisiae, such as heat-shock genes and glucose-repressed genes (Bataillé et al., 1988, 1991). We followed the change in protein synthesis until glucose was exhausted from the medium. Whereas little change was observed between cells growing exponentially on glucose with and without cAMP, the numerous changes in patterns of proteins synthesized after glucose exhaustion were mostly prevented by the presence of cAMP in the culture medium.

\section{METHODS}

Yeast strain. The OL556 diploid strain used in these experiments was obtained by conjugating OL554 ( $\alpha$ cdc25-5 his 3 leu2 $\mathrm{rca} 1 / \mathrm{pde} 2 \mathrm{ura}$ ) and OL555 (a cdc25-5 bis 3 leu2 $\operatorname{trp} 1 \mathrm{rca} 1 / \mathrm{pde} 2$ ura3). These two haploids are meiotic products of the cross of S150-2B (a bis3 leu2-112 trp1-289 ura3-52; Daignan-Fornier et al., 1988) with OL520-2 ( $\alpha$ cdc25-5 bis3 leu2 rca1/pde2 ura3; our laboratory). In addition to their genotypes, these haploid strains have also been selected for their permeability to the chromogenic substrate X-Gal by the blue colour of the clones when transformed with $l a c Z$ as a reporter gene inserted into a plasmid.

Culture conditions. Supplemented minimal medium, YNBS, contained $0.17 \%$ yeast nitrogen base without ammonium sulfate and amino acids, $0.5 \%$ ammonium sulfate, $2 \%(\mathrm{w} / \mathrm{v})$ glucose, $25 \mu \mathrm{g}$ inositol ml $\mathrm{m}^{-1}, 800 \mu \mathrm{g}$ leucine $\mathrm{ml}^{-1}, 100 \mu \mathrm{g}$ isoleucine $\mathrm{ml}^{-1}$, $100 \mu \mathrm{g}$ valine $\mathrm{ml}^{-1}, 300 \mu \mathrm{g}$ histidine $\mathrm{ml}^{-1}, 100 \mu \mathrm{g}$ uracil ml $\mathrm{m}^{-1}$ and $85 \mathrm{mM}$ succinate $/ \mathrm{NaOH}, \mathrm{pH}$ 5.8. Complete medium contained $1 \%(\mathrm{w} / \mathrm{v})$ yeast extract, $2 \%(\mathrm{w} / \mathrm{v})$ bactopeptone and $1 \%(\mathrm{w} / \mathrm{v})$ glucose (YPD) or $2 \%(\mathrm{v} / \mathrm{v})$ ethanol (YPE). An overnight preculture grown at $26^{\circ} \mathrm{C}$ in the required medium in the absence of cAMP was used to inoculate the culture at $10^{6}$ cells $\mathrm{ml}^{-1}$. Growth was continued (at the indicated temperature) in the absence or the presence of $3 \mathrm{mM}$ cAMP.

\footnotetext{
Measurement of cell density and budding and estimation of viability. The cell density in the culture was estimated either by measuring the $\mathrm{OD}_{710}$ with a Jenway 6061 colorimeter, or by counting the cell number under the microscope with a haemocytometer. In this latter case, a minimum of 200 budded and unbudded cells were counted after separation by mild sonication. Viability was determined by spreading appropriate dilutions of the sonicated culture on complete solid medium and counting c.f.u. after $3 \mathrm{~d}$ at $26^{\circ} \mathrm{C}$.
}

Soluble protein content of cells. A sample of culture containing $2-5 \times 10^{8}$ cells was withdrawn, washed once and concentrated in $1 \mathrm{ml}$ ice-cold $100 \mathrm{mM}$ Tris $/ \mathrm{HCl}, \mathrm{pH} 8$, containing $1 \mathrm{mM}$ dithiothreitol and $20 \%(\mathrm{v} / \mathrm{v})$ glycerol (cell-breakage buffer). Cell concentration of the concentrated sample was measured by counting under the microscope. For each sample, three independent extractions were performed on $300 \mu$ l of the concentrated sample in cell-breakage buffer by vortexing at $4^{\circ} \mathrm{C}$ with $300 \mathrm{mg}$ glass beads $(0.45-0.5 \mathrm{~mm}$ diameter) until less than $1 \%$ of intact cells were still visible by light microscopy. Extracts were clarified by centrifuging for $15 \mathrm{~min}$ in a microfuge at $18000 \mathrm{~g}$ at $4{ }^{\circ} \mathrm{C}$. Protein concentration was measured in each extract by using the Bradford (1976) dye-binding assay (Bio-Rad reagent).

Glucose measurement. The concentration of glucose in the culture medium was measured enzymically with glucose oxidase, using the Sigma Diagnostic Glucose reagent kit no. 510-A.

Radioactive labelling of proteins, preparation of cell extracts and 2-D gel electrophoresis were as described by Boucherie $e t a l$. (1995).

\section{RESULTS}

\section{Effect of CAMP on growth of strain OL556 in minimal glucose medium}

The intracellular level of cAMP can be modulated in diploid strain OL556 homozygous for $c d c 25-5$ and rca1/pde2 mutations. In this strain, cAMP is not synthesized at $37^{\circ} \mathrm{C}$ due to the $c d c 25-5$ mutation (Camonis et al., 1986). Resulting growth arrest can be rescued by exogenously added cAMP as a consequence of the rca1/pde2 mutation which affects the high-affinity phosphodiesterase (Wilson et al., 1993). In the absence of this mutation, very high concentrations of exogenous cAMP are insufficient to complement the defect in cAMP synthesis. However, when the high-affinity phosphodiesterase was inactive, the intracellular level of cAMP was $50 \mu \mathrm{M}$ when $3 \mathrm{mM}$ cAMP was added exogenously, this being sufficient to complement the defect of cAMP synthesis (Wilson et al., 1993). In our strain (OL556), a sufficient level of cAMP was produced at the permissive temperature to allow cell division. When $3 \mathrm{mM}$ cAMP was added to the medium with $2 \%$ glucose at $28{ }^{\circ} \mathrm{C}$, a slight increase of the generation time was observed (Fig. 1a; Table 1). This prolonged cell cycle resulted in the formation of larger cells, leading to a higher coefficient of turbidity (Table 1) as already reported (Baroni et al., 1989). We found that the protein content of these cells was three- to fourfold higher with cAMP than without (Table 1) and, as a consequence, the number of cells generated for a given amount of glucose was fourfold lower in cAMPtreated cultures (Fig. 1a). These phenotypes are a mark of the high level of PKA activity due to the $r c a 1 / p d e 2$ mutation and the addition of cAMP. Growth arrest occurred simultaneously with the exhaustion of glucose from the medium in both the presence and absence of cAMP (Fig. 1b) and corresponded with diauxic lag phase (Lewis et al., 1993). When glucose was exhausted, the ratio of budded cells, which decreased to less than $10 \%$ in untreated cells, was maintained up to $35 \%$ in the cAMPtreated culture. High cell viability was maintained 

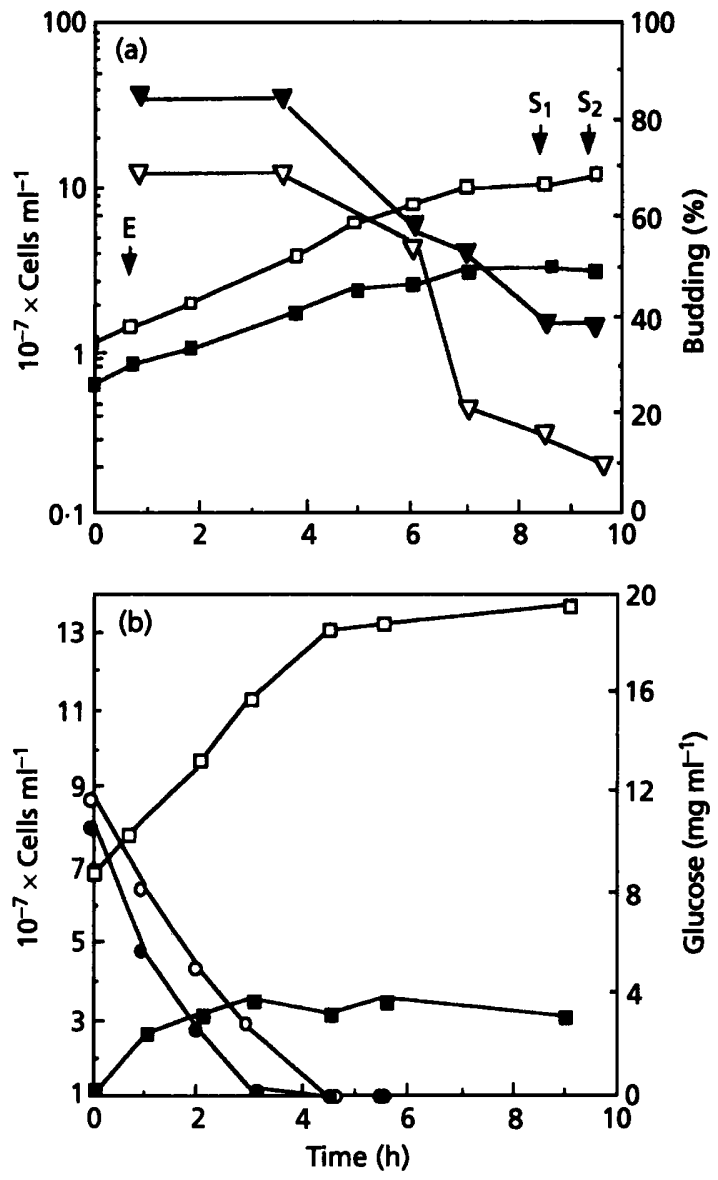

Fig. 1. (a) Growth of the OL556 strain in YNBS medium in the absence (open symbols) or in the presence (filled symbols) of $3 \mathrm{mM}$ CAMP. Culture conditions are described in Methods. $\square, \mathbf{0}$, Cells $\mathrm{ml}^{-1} ; \Delta, \Delta$, percentage of budded cells. Arrows indicate times, in exponential growth phase and lag phase, at which samples have been withdrawn to perform the measurements indicated in Table 1 and radioactive labelling of proteins. (b) Time-course of glucose depletion in the culture of strain OL556 in YNBS in the absence (open symbols) or the presence (filled symbols) of $3 \mathrm{mM}$ CAMP. $\square, \square$, Cells $\mathrm{ml}^{-1} ; 0$, - glucose concentration in the medium. throughout the experimental period irrespective of cAMP addition (Table 1).

\section{Pattern of protein synthesis during exponential growth and at the diauxic transition}

In order to assess the effect of cAMP on gene expression during growth on glucose, we examined the 2-D protein patterns after a pulse of $\left[{ }^{35} \mathrm{~S}\right]$ methionine. Two different growth stages were considered: exponential growth phase and the arrested phase after glucose exhaustion. For each stage, cells grown in the absence or the presence of cAMP were compared. We used an improved 2-D gel electrophoresis method derived from the $\mathrm{O}^{\prime}$ Farrell technique, allowing resolution of soluble proteins with a pI ranging from 4.2 to 6.8 and with an $M_{\mathrm{r}}$ between 15000 and 150000 (Boucherie et al., 1995).

As shown in Fig. 2, the patterns from cells growing exponentially on glucose, without (Fig. 2a) or with (Fig. 2b) cAMP, were very similar. These patterns closely resembled the pattern of wild-type cells growing exponentially on a fermentable carbon source. Under these conditions, the major spots corresponded to glycolytic enzymes (Boucherie et al., 1995). Some of them are numbered on the patterns for reference and are listed in Table 2. Differences concerning only three polypeptides (spots 11,12 and 13) emerged from the comparison of Fig. 2(a) and (b). Spots 11 and 12 were absent in cells grown without CAMP. The polypeptide corresponding to spot 13 was synthesized under both culture conditions but its relative rate of synthesis was markedly increased in the presence of cAMP. None of these spots have yet been identified.

In contrast, the pattern of protein synthesis after glucose exhaustion was dramatically different between cells grown without (Fig. 2c) or with (Fig. 2d) cAMP. Two experiments, performed $120 \mathrm{~min}$ and $180 \mathrm{~min}$ after growth arrest (Fig. 1a), gave a similar pattern. They differed only in the amount of protein synthesized, which was reduced

\section{Table 1. Effect of CAMP on OL556 cells grown in YNBS medium}

Percentage of budding cells and cell viability, protein content in the culture and cell protein content have been measured on samples $\mathrm{E}$, $\mathrm{E}+\mathrm{cAMP}, \mathrm{S}_{2}$ and $\mathrm{S}_{2}+\mathrm{cAMP}$ withdrawn from the culture described in Fig. 1, as outlined in Methods.

\begin{tabular}{|c|c|c|c|c|c|c|}
\hline Growth phase & $\begin{array}{c}\text { Generation } \\
\text { time } \\
\text { (min)* }\end{array}$ & $\begin{array}{c}\text { Budding } \\
(\%)\end{array}$ & $\begin{array}{l}\text { Viability } \\
(\%)\end{array}$ & $\begin{array}{c}10^{-7} \times \text { Cells } \\
\text { per } \text { OD }_{710} \\
\text { unit } \dagger\end{array}$ & $\begin{array}{c}\text { Soluble protein } \\
{\left[\mathrm{mg}(\mathrm{ml} \text { culture })^{-1}\right] \ddagger}\end{array}$ & $\begin{array}{c}\text { Cell soluble } \\
\text { protein content } \\
\left(\text { pg cell }{ }^{-1}\right) \ddagger\end{array}$ \\
\hline $\mathrm{E}$ & 126 & 71 & 92 & $1 \cdot 4 \pm 0 \cdot 16$ & $0.087 \pm 0.021$ & $5 \cdot 5$ \\
\hline $\mathrm{E}+\mathrm{cAMP}$ & 165 & 85 & 100 & $0.82 \pm 0.08$ & $0.114 \pm 0.003$ & $15 \cdot 1$ \\
\hline $\mathrm{S}_{2}$ & & 9 & 62 & 1.45 & $0.47 \pm 0.03$ & $4 \cdot 85$ \\
\hline $\mathrm{S}_{2}+\mathrm{cAMP}$ & & 35 & 70 & 0.71 & $0.59 \pm 0.04$ & $18 \cdot 3$ \\
\hline
\end{tabular}

* Generation times were measured on the growth curves in Fig. 1.

$\dagger$ The ratio ( \pm standard deviation) of the cell concentration to the turbidity in exponential growth phase is the mean of six values measured during this exponential growth phase. In stationary phase, the ratio indicated is the one measured in samples $\mathrm{S}_{2}$ and $\mathrm{S}_{2}+\mathrm{cAMP}$.

$\ddagger$ These values are the means of three independent measurements. 

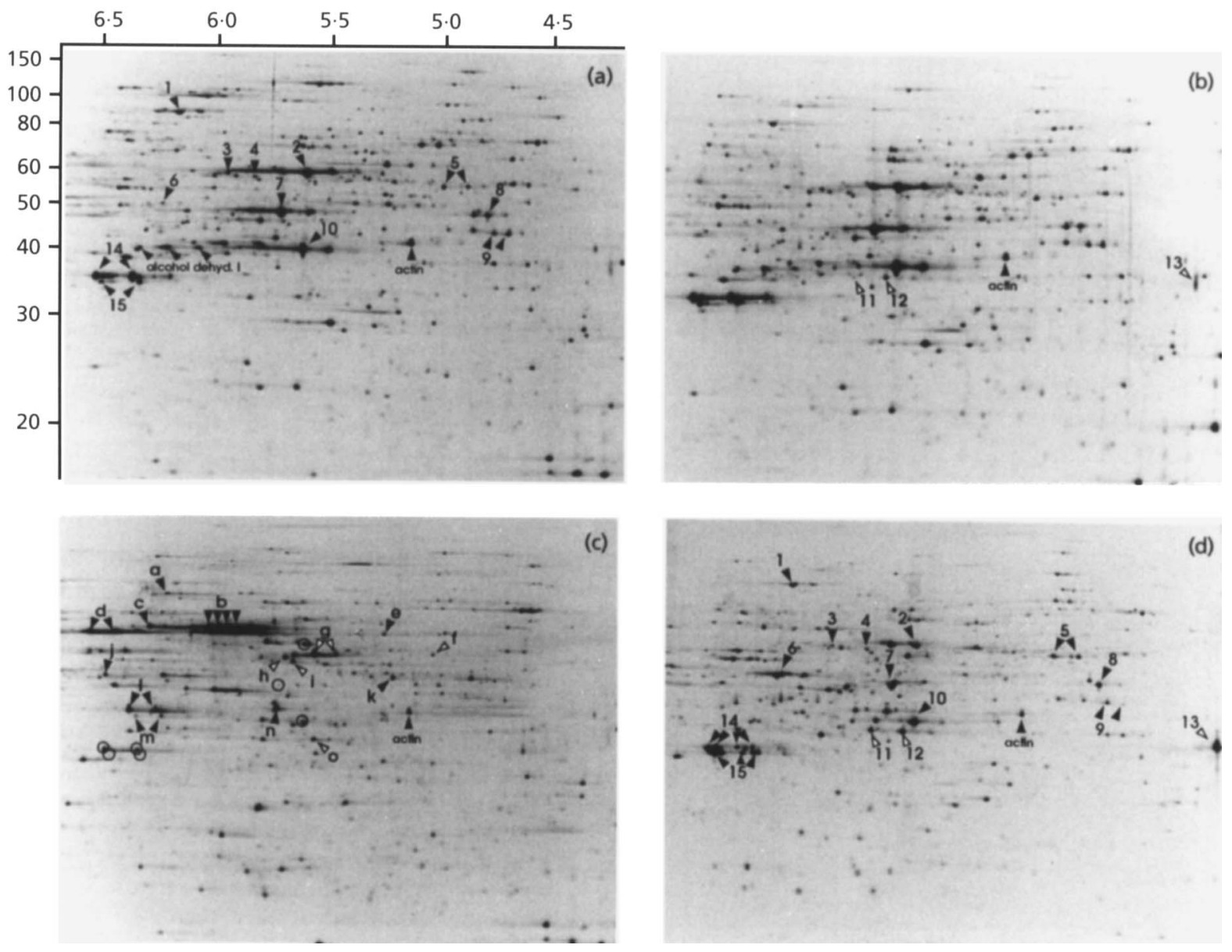

Fig. 2. 2-D protein patterns from cells labelled at times indicated by arrows $\left(E, S_{1}, S_{2}\right)$ on Fig. 1. Two millilitres of samples $E$ and $E+$ CAMP were labelled for $30 \mathrm{~min}$, whilst $0.3 \mathrm{ml}$ samples $S_{1}$ and $S_{2}$ and $0.6 \mathrm{ml}$ samples $S_{1}+$ CAMP and $S_{2}+C A M P$ were labelled for $50 \mathrm{~min}$ with $3.7 \times 10^{9} \mathrm{~Bq} \mathrm{[}{ }^{35}$ S]methionine $\left(>3.7 \times 10^{13} \mathrm{~Bq} \mathrm{mmol}{ }^{-1}\right.$, Amersham). After the labelling period, the cells were washed and extracted in $200 \mu \mathrm{l}$ extraction buffer. In this experiment, methionine incorporated was: in $\mathrm{E}, 4.75 \times 10^{7}$ c.p.m in $2.9 \times 10^{7}$ cells; in $\mathrm{E}+$ CAMP, $4.8 \times 10^{7}$ c.p.m. in $1.65 \times 10^{7}$ cells; in $S_{1}, 3.6 \times 10^{7}$ c.p.m. in $3 \times 10^{7}$ cells; in $S_{1}+$ CAMP, $7.2 \times 10^{6}$ c.p.m. in $1.9 \times 10^{7}$ cells. Separation of proteins was done by 2-D gel electrophoresis. An aliquot $(15 \mu \mathrm{l})$ of each extract was loaded on the first dimension gel. Radioactivity on the gels was revealed using a Phospholmager (Molecular Dynamics). Adjustment of image intensities has been done to have approximately the same intensity for the actin spot on the four images. (a) Protein pattern from aliquot $E$; (b) protein pattern from aliquot $E$ + CAMP; (c) protein pattern from aliquot $S_{1}$; (d) protein pattern from aliquot $S_{1}+$ CAMP. Spots indicated by black arrowheads on (a) and (d) correspond to proteins listed in class $A$ of Table 2 . White arrowheads on (b) and (d) indicate spots corresponding to proteins induced by CAMP. Circles on (c) indicate reduction or disappearance of spots $2,7,10,13$ and 15. Black arrowheads and white arrowheads on (c) indicate, respectively, major glucose-repressed proteins and stress proteins present on (c) and absent on (a).

after $180 \mathrm{~min}$. The pattern of protein synthesis was markedly different from exponentially growing cells (Fig. $2 \mathrm{a}, \mathrm{c}) 120 \mathrm{~min}$ after growth arrest without cAMP as previously reported by Bataillé $e t$ al. (1991) and Boucherie (1985). In particular, glycolytic enzymes were either absent, e.g. enolase B (spot 7) and glyceraldehyde-3phosphate dehydrogenase $B$ (spot 15), or only detectable as minor spots, e.g. pyruvate decarboxylase (spot 2), fructose-1,6-bisphosphate aldolase (spot 10) and glyceraldehyde-3-phosphate dehydrogenase C (spot 14). Synthesis of new polypeptides was induced at this time. These belonged to two sets of proteins, proteins subject to glucose repression and stress-induced proteins (Bataillé et al., 1991).
As shown in Fig. 2(d), the presence of cAMP in the culture medium interfered with most of the changes induced by glucose exhaustion. The relative rates of synthesis of individual proteins could be estimated roughly by comparison of the intensity of the corresponding spots to the intensity of the actin spot. From this comparison, it was observed that the relative rate of synthesis was maintained for most of the major proteins, normally repressed after glucose exhaustion. A subset of these proteins, chosen because they have been already identified, is indicated in Fig. 2(a,d) and is reported in Table 2 (class A). The proteins correspond mostly to glycolytic enzymes. Among the proteins synthesized during exponential phase, two proteins, enolase A (spot 6) 
Table 2. Proteins whose synthesis is modified by CAMP

Spot number or letter mentioned in this table corresponds to the number or letter in Fig. 2.

Identification of the spots has been previously reported by Bataille et al. (1991), Boucherie (1985) and

Boucherie et al. (1995). Their presence or their absence on 2-D maps (Fig. $2 a-d$ ) is indicated by + or

-. The number of crosses represents the spot intensity compared to the same spot in Fig. 2(a). CCR, proteins whose synthesis is repressed by glucose; HS, proteins whose synthesis is induced by heat-

shock. *, Unidentified protein.

\begin{tabular}{|c|c|c|c|c|c|c|c|}
\hline $\begin{array}{l}\text { Number on } \\
\text { the maps }\end{array}$ & Gene & Protein & $\mathbf{E}$ & $\begin{array}{c}\mathbf{E}+ \\
\mathbf{c A M P}\end{array}$ & $\mathbf{S}$ & $\begin{array}{c}\text { S+ } \\
\text { cAMP }\end{array}$ & $\begin{array}{l}\text { Regu- } \\
\text { lation }\end{array}$ \\
\hline \multicolumn{8}{|l|}{ Class A } \\
\hline 1 & MET6 & Methionine synthase & + & + & - & + & \\
\hline 2 & $P D C 1$ & Pyruvate decarboxylase & + & + & $-/+$ & + & \\
\hline 3 & PGI1 & Phosphoglucoisomerase & + & + & - & $+1-$ & \\
\hline 4 & $Z W F 1$ & $\begin{array}{l}\text { Glucose-6-phosphate } \\
\text { dehydrogenase }\end{array}$ & + & + & - & $+1-$ & \\
\hline 5 & $H X K 2$ & Hexokinase PII & + & + & - & + & \\
\hline 6 & ENO1 & Enolase A & + & + & - & +++ & \\
\hline 7 & ENO2 & Enolase B & + & + & - & + & \\
\hline 8 & SAM1 & $\begin{array}{l}\text { S-Adenosyl-methionine } \\
\text { synthetase }\end{array}$ & + & + & - & + & \\
\hline 9 & TIF1 & Translation initiation factor $4 \mathrm{~A}$ & + & + & - & $+/-$ & \\
\hline 10 & $F B A 1$ & Fructose-bisphosphate aldolase & + & + & - & + & \\
\hline 14 & $T D H 3$ & $\begin{array}{l}\text { Glyceraldehyde-3-phosphate } \\
\text { dehydrogenase C }\end{array}$ & + & + & $+/-$ & + & \\
\hline 15 & TDH2 & $\begin{array}{l}\text { Glyceraldehyde-3-phosphate } \\
\text { dehydrogenase B }\end{array}$ & + & + & - & + & \\
\hline \multicolumn{8}{|l|}{ Class B } \\
\hline 10 & $*$ & $*$ & - & $-/+$ & - & + & \\
\hline 2 & $*$ & $*$ & - & + & - & + & \\
\hline 13 & $*$ & $*$ & - & $-1+$ & - & ++ & \\
\hline \multicolumn{8}{|l|}{ Class C } \\
\hline $\mathrm{a}$ & $*$ & $*$ & - & - & + & - & CCR \\
\hline $\mathrm{b}$ & ICL1 & Isocitrate lyase & - & - & + & - & CCR \\
\hline c & $*$ & $*$ & - & - & + & - & CCR \\
\hline d & $*$ & $*$ & - & - & + & - & CCR \\
\hline e & $*$ & $*$ & - & - & + & - & CCR \\
\hline $\mathrm{f}$ & $H X K 1$ & Hexokinase PI & - & - & + & - & CCR/HS \\
\hline $\mathrm{g}$ & $*$ & $*$ & - & - & + & - & HS \\
\hline $\mathrm{h}$ & $*$ & $*$ & - & - & + & - & HS \\
\hline $\mathrm{i}$ & $*$ & $*$ & - & - & + & - & HS \\
\hline j & $*$ & $*$ & - & - & + & - & CCR \\
\hline $\mathrm{k}$ & $*$ & $*$ & - & - & + & - & CCR \\
\hline 1 & $*$ & $*$ & - & - & + & - & $\mathrm{CCR}$ \\
\hline $\mathrm{m}$ & $A D H 2$ & Alcohol dehydrogenase II & - & - & + & - & CCR \\
\hline $\mathrm{n}$ & $*$ & $*$ & - & - & + & - & CCR \\
\hline o & $*$ & $*$ & - & - & + & - & HS \\
\hline
\end{tabular}

and alcohol dehydrogenase I, seemed at a first glance to have a different behaviour. The relative rate of synthesis of enolase A was higher after glucose exhaustion than during exponential phase. Alcohol dehydrogenase I, which corresponded to a major spot during exponential phase, became undetectable after glucose exhaustion, even in the presence of cAMP. Previous investigations had shown that the relative rate of synthesis of enolase A progressively increased during the time-course of growth on glucose. During the same period, the relative rate of synthesis of alcohol dehydrogenase I progressively decreased (Bataillé et al., 1991; Boucherie, 1985). These observations concerning enolase $\mathrm{A}$ and alcohol dehydrogenase I probably reflect changes in the relative level of synthesis of these enzymes normally occurring prior to glucose exhaustion rather than the existence of a particular behaviour of these enzymes in response to cAMP.

A second dramatic effect of cAMP was to prevent the synthesis of proteins normally induced in response to 

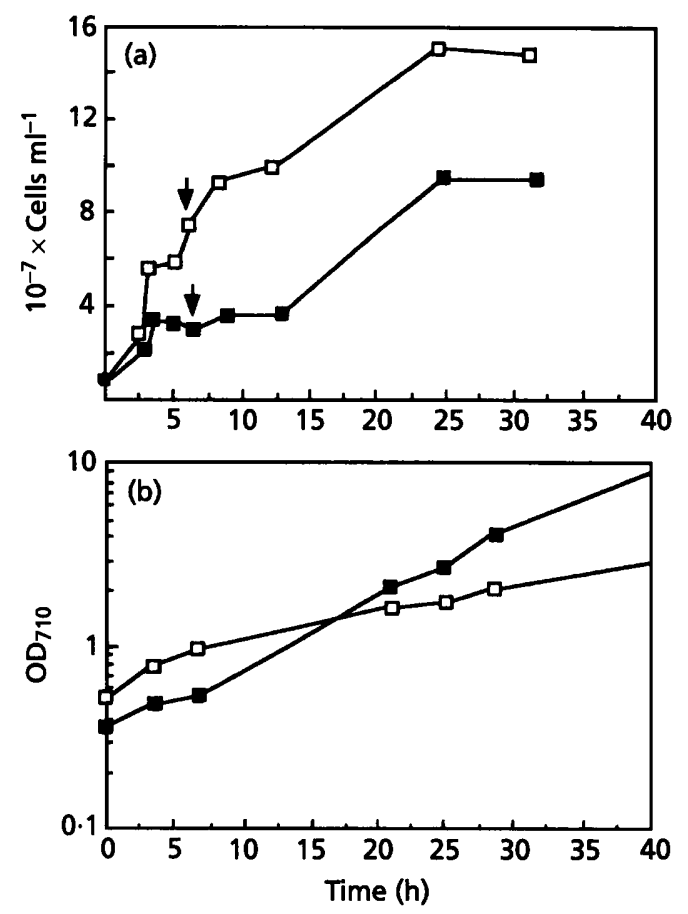

Fig. 3. YPD medium in the absence ( $\square$ ) or in the presence ( $\square$ ) of CAMP was inoculated with $10^{6}$ cells $\mathrm{ml}^{-1}$ using a preculture of strain OL556 in YPD at $27^{\circ} \mathrm{C}$. Arrows indicate the time at which aliquots were diluted 10 times in prewarmed $Y P E \pm 3 \mathrm{mM}$ CAMP. (a) Growth in YPD; (b) growth in YPE at $27^{\circ} \mathrm{C}$ after dilution from the YPD culture.

glucose exhaustion. Comparison of Fig. 2(c) and (d) gave evidence that in the presence of cAMP, none of the proteins subject to glucose repression were induced $2 \mathrm{~h}$ after glucose exhaustion. In the same way, induction of synthesis of stress-induced proteins was not detected. The same pattern was observed $3 \mathrm{~h}$ after glucose exhaustion in the presence of cAMP (data not shown). Some of these non-inducible proteins are listed in Table 2, class C: 11 are the products of glucose-repressed genes, among them isocitrate lyase, hexokinase PI and alcohol dehydrogenase II; 4 are the products of stress-induced genes.

Finally, comparison of protein patterns of cells which have exhausted their glucose supply in the absence or the presence of cAMP also showed differences which were not related to changes normally occurring when glucose is consumed. Spots 11, 12 and 13, already detectable in cells growing exponentially on glucose, were abundantly synthesized in the presence of cAMP and were undetectable in the absence of cAMP (Fig. 2d; Table 2, class B).

\section{CAMP delays, but does not prevent, post-diauxic growth}

Growth of the OL556 strain on rich medium containing $1 \%$ glucose in the presence or absence of $3 \mathrm{mM}$ cAMP was followed to test the ability of the cells to switch to respiratory growth on ethanol. YPE medium was used in preference to minimal medium because the generation time on ethanol of this strain was shorter on rich medium than on minimal medium. Growth was performed at $27^{\circ} \mathrm{C}$ because this strain is thermosensitive at $30^{\circ} \mathrm{C}$ in ethanol medium, due to the $c d c 25-5$ mutation. In the absence of cAMP, a delay ( $2-3 \mathrm{~h}$ ) was observed before a doubling of the cell number. In the presence of $3 \mathrm{mM}$ cAMP, this delay was increased to $10 \mathrm{~h}$ (Fig. 3). When the arrested cells were diluted in YPE without cAMP, no lag was observed before recovery of the exponential growth. When cAMP was present, recovery of exponential growth was observed after a lag of $5 \mathrm{~h}$ with a generation time even shorter than in the absence of cAMP (Fig. 3). These observations indicate that cAMP delayed the switch to respiratory growth, but that growth on ethanol was not prevented by cAMP. Moreover, cAMP complemented the weak growth defect of the OL556 strain due to the cdc25-5 mutation.

\section{DISCUSSION}

The use of the rca1/pde2 mutant and exogenous cAMP permits comparison of the properties of the same strain having a wild-type intracellular level of cAMP (in the absence of exogenous cAMP) and having a high cAMP level (in the presence of exogenous cAMP). The addition of cAMP to the medium leads to large cells and an increase in cell protein content, which is a mark of a high intracellular cAMP level. These cells remain viable and divide normally, which suggests that this high cAMP level has no deleterious effects. Moreover, the phenotypes of nitrogen starvation, heat-shock and sensitivity, as well as reduction in glycogen accumulation, usually associated with deregulation of the PKA, are weaker in this strain grown in the presence of cAMP than in a $b c y 1$ strain (data not shown). This strain has already been used to demonstrate cAMP effects on various cellular phenomena (Baroni et al., 1989; Bissinger et al., 1989; Tokiwa et al., 1994).

In this report, we have analysed the changes in the protein synthesis patterns in S. cerevisiae induced by exogenously added cAMP during and after growth on glucose as sole carbon source. Use of an improved 2-D gel electrophoresis system allowed the simultaneous visualization of a large subset of cellular proteins, in the pI range 4.2 to 6.8 and $M_{\mathrm{r}}$ range from 15000 to 150000 , which is representative of the synthetic capability of the cell as it corresponds to $30 \%$ of total soluble proteins (Boucherie et al., 1995). Almost 100 spots currently are identified, and the number of identified spots is rapidly increasing with analyses associated with the yeast genome sequencing projects.

During exponential growth on glucose, the usual pattern of gene expression was observed with a high level of expression of genes involved in glycolysis. In the pde $2 /$ rca 1 mutant, the presence of cAMP in the medium did not cause large modifications in the protein pattern of the cell, which again indicates that the cell physiology was 
not greatly modified by the increased intracellular cAMP level. We detected only three differences corresponding to proteins induced in cells grown with cAMP in the medium. Synthesis of these proteins was maintained after glucose exhaustion. Their identification would be of interest because they might be critical effectors of the cAMP pathway. A two- to threefold stimulation of the transactivation potential of RAP1 by PKA has been reported (Klein \& Struhl, 1994). Nevertheless, we have not detected any consequences of this control. Ribosomal proteins, whose transcription is activated by RAP1, are not included in our analysis because they are too basic. A possible explanation, for other non-ribosomal proteins under RAP1 control, is that the presence of glucose leads to an intermediate level phosphorylation of RAP1 and other transcriptional activators, and that the small variation due to the addition of cAMP was not detected in our analysis.

The most dramatic observation of our analysis was the difference in the pattern of protein synthesis after glucose exhaustion with and without cAMP. Consumption of glucose is known to trigger several modifications of gene expression, and the pattern observed without cAMP was similar to that previously described in other strains (Bataillé et al., 1991). There was a general reduction in protein synthesis with a marked repression of glucoseinduced proteins, while glucose-repressed proteins and heat-shock proteins were induced, at least transiently. The presence of cAMP in glucose-deprived medium interfered dramatically with these changes. cAMP did not prevent the drop in total synthetic capability, as judged from the incorporation of radioactive methionine, but it maintained the protein distribution of glucose-grown cells as if glucose was still present. Indeed glycolytic enzymes were not repressed and all the known glucose-repressed proteins were not induced. These results illustrate the interference of the Ras/cAMP pathway with the expression of genes controlled by glucose. Transient induction of some heat-shock proteins, which is normally associated with glucose exhaustion, was also prevented. This observation is in agreement with previous data indicating a negative effect of cAMP on the transcriptional heat-shock response of several genes. We suspect that the genes which encode these proteins belong to the class of genes induced by a variety of stresses and negatively regulated by cAMP through stress response elements (Marchler et al., 1993).

This is the first time that such a large pleiotropic effect on gene expression has been reported for cAMP-treated cells. The major qualitative changes were observed at the end of growth on glucose. This stage corresponds to the diauxic shift, during which cells switch from the fermentative to the respiratory programme of gene expression. At the end of growth on glucose, mRNA of positive regulators of the cAMP pathway such as $C D C 25, \mathrm{R} A S 2$ and $C D C 35$ is reduced, whereas mRNA of negative regulators such as $\operatorname{IR} A 1$ and $I \mathrm{R} A 2$ accumulates, leading to a reduction in cAMP levels within cells (François et al., 1984; Russel et al., 1993). This reduction is required for the diauxic shift, since this transition was delayed by an excess of cAMP in strain OL556, as described in this paper, and even prevented in other strains (Russel et al., 1993). Our results further establish the involvement of cAMP regulation in this transition and can explain the growth defect on acetate of bcy1 strains (Toda et al., 1987). When a high level of cAMP was artificially maintained, changes in gene expression were delayed or prevented as documented in this report. These results lead us to conclude that this change in gene expression pattern, which requires a drop in PKA activity, is essential for the switch from fermentative to non-fermentative conditions. Nevertheless, the cAMP pathway does not impair growth on respiratory carbon sources as we describe in this paper and it is even essential for growth on any carbon source. Thus, a decrease of the cAMP level is important for the occurrence of the diauxic transition but not for steady-state growth on non-fermentable carbon sources. Taking these data into account, we propose the following model for the role of the cAMP-signalling pathway on regulation of gene expression. It will reinforce the activity or the stability of many transcriptional factors by modification, rather than determining their activity. In this way, it will stabilize a programme of gene expression defined by a set of transcriptional regulators adapted to a defined environment. If the environment changes, by glucose exhaustion for example, these cAMP-dependent modifications have to be removed by a transient reduction of the cAMP pathway activity to allow these transcriptional regulators to change their activity in response to the new environmental conditions. If cAMP is maintained at a high constitutive level, it will antagonize the change in gene expression. As an illustration, we observed that the maintenance of cAMP at a high level maintains the programme of gene expression adapted to glucose conditions and prevents the setting up of the programme adapted to non-fermentable carbon sources. Such a role for cAMP implies a very pleiotropic effect, acting either positively or negatively on many transactivators and repressors. It explains the pleiotropic phenotype associated with deregulation of this pathway and reinforces the view that this pathway serves as a signalling pathway during a transition period to adapt cells to new conditions (Thevelein, 1994). In this model, the phenotype of sensitivity to ammonium starvation and heatshock, observed in mutants where the PKA is hyperactive, can be re-interpreted as the inability of the yeast cell to change its gene expression programme in response to variations in the environment. This model is not contradictory with the observation that in $t p k^{\mathrm{w}} b c y 1$ mutants, the cellular response to environmental changes is apparently normal although the pathway is no longer regulated by cAMP. In this case, the phosphorylation is maintained at a very low level and the change in the gene expression programme is less dependent on a decrease in PKA activity.

\section{ACKNOWLEDGEMENTS}

We thank Christelle Monribot for technical assistance and Carl Mann (CEA, Saclay, France) for his critical reading of the manuscript. D. Tadi is supported by a fellowship from the 
Ministère de la Recherche et de l'Enseignement Supérieur. This work was supported by grants from the 'Association pour la Recherche contre le Cancer' and from the 'Groupement de Recherche et d'Etude sur les Génomes'.

\section{REFERENCES}

Adams, S. R., Harootunian, A. T., Buechler, Y. J., Taylor, S. S. \& Tsien, R. Y. (1991). Fluorescence ratio imaging of cyclic AMP in single cells. Nature 342, 694-697.

Baroni, M. D., Martegani, E., Monti, P. \& Alberghina, L. (1989). Cell size modulation by $C D C 25$ and $R A S 2$ genes in Saccbaromyces cerevisiae. Mol Cell Biol 9, 2715-2723.

Bataillé, N., Thoraval, D. \& Boucherie, H. (1988). Two-dimensional gel analysis of yeast proteins: application to the study of changes in the levels of major polypeptides of $S$. cerevisiae depending on the fermentable or non fermentable nature of the carbon source. Electrophoresis 9, 774-780.

Bataillé, N., Régnacq, M. \& Boucherie, H. (1991). Induction of a heat-shock-type response in Saccharomyces cerevisiae following glucose limitation. Yeast 7, 367-378.

Bissinger, P. H., Wieser, R., Hamilton, B. \& Ruis, H. (1989). Control of Saccharomyces cerevisiae catalase gene (CTT1) expression by nutrient supply via the ras-cyclic AMP pathway. Mol Cell Biol 9, 1309-1315.

Boorstein, W. R. \& Craig, E. A. (1990). Regulation of a yeast HSP70 by a cAMP responsive transcriptional control element. EMBO J $\mathbf{9}$, 2543-2553.

Boucherie, H. (1985). Protein synthesis during transition and stationary phases under glucose limitation. J Bacteriol 161, 385-392.

Boucherie, H., Dujardin, G., Kermogant, M., Monribot, C., Slonimsky, P. \& Perrot, M. (1995). Two dimensional protein map of Saccharomyces cerevisiae: construction of a gene-protein index. Yeast 11, 601-613.

Boy-Marcotte, E., Garreau, H. \& Jacquet, M. (1987). Cyclic AMP controls the switch between division cycle and resting state programs in response to ammonium availability in Saccharomyces cerevisiae. Yeast 3, 85-93.

Bradford, M. M. (1976). A rapid and sensitive method for the quantitation of microgram quantities of protein utilizing the principle of protein-dye binding. Anal Biochem 72, 248-254.

Brindle, P. K. \& Montminy, M. R. (1992). The CREB family of transcription activators. Curr Opin Genet \& Dev 2, 199-204.

Camonis, J. H., Kalékine, M., Gondré, B., Garreau, H., BoyMarcotte, E. \& Jacquet, M. (1986). Characterization, cloning and sequence analysis of the $C D C 25$ gene which controls the cyclic AMP level of Saccharomyces cerevisiae. EMBO J 5, 375-380.

Cherry, J. R., Johnson, T. R., Dollard, C., Shuster, J. R. \& Denis, C. L. (1989). Cyclic AMP dependent protein kinase phosphorylates and inactivates the yeast transcriptional activator ADR1. Cell 56, 409-419.

Daignan-Fornier, B., Vallens, M., Lemire, B. D. \& BolotinFukuhara, M. (1988). In vivo functional characterization of a yeast nucleotide sequence: construction of a mini-Mu derivate adapted to yeast. Gene 62, 45-54.

Denis, C. L., Fontaine, S. C., Chase, D., Kemp, B. E. \& Bemis, L. T. (1992). $A D R 1^{\mathrm{c}}$ mutations enhance the ability of ADR 1 to activate transcription by a mechanism that is independent of effects on cyclic AMP-dependent protein kinase phosphorylation of Ser-230. Mol Cell Biol 12, 1507-1514.

Engelberg, D., Klein, C., Martinetto, H., Struhl, K. \& Karin, M. (1994a). The UV response involving the Ras signalling pathway and AP-1 transcription factors is conserved between yeast and mammals. Cell 77, 381-390.

Engelberg, D., Zandi, E., Parker, C. S. \& Karin, M. (1994b). The yeast and mammalian Ras pathways control transcription of heat shock genes independently of heat shock transcription factor. Mol Cell Biol 14, 4929-4937.

François, J. M., Schaftingen, E. V. \& Hers, H. G. (1984). The mechanism by which glucose increases fructose-2,6-bisphosphate concentration in Saccharomyces cerevisiae. A cyclic-AMP-dependent activation of phosphofructokinase 2. Eur J Biochem 145, 187-193.

François, J., Eraso, P. \& Gancedo, C. (1987). Changes in the concentration of cAMP, fructose 2,6-bisphosphate and related metabolites and enzymes in Saccharomyces cerevisiae during growth on glucose. Eur J Biochem 164, 369-373.

François, J. M., Thompson-Jaeger, S., Skroch, J., Zellenka, U., Spevak, W. \& Tatchell, K. (1992). $G A C 1$ may encode a regulatory subunit for protein phosphatase type 1 in Saccharomyces cerevisiae. EMBO J 11, 87-96.

Gimeno, C. J., Ljungdahl, P. O., Styles, C. A. \& Fink, G. R. (1992). Unipolar cell divisions in the yeast $S$. cerevisiae lead to filamentous growth: regulation by starvation and RAS. Cell 68, 1077-1090.

Hardy, T. A., Huang, D. \& Roach, P. J. (1994). Interactions between cAMP dependent and SNF1 protein kinases in the control of glycogen accumulation in Saccharomyces cerevisiae. J Biol Chem 269, 27907-27913.

Kataoka, T., Powers, S., McGill, C., Fasano, O., Strathern, J., Broach, J. \& Wigler, M. (1984). Genetic analysis of yeast $R A S 1$ and RAS2 genes. Cell 37, 437-445.

Kinney, A. J. \& Carman, G. M. (1988). Phosphorylation of the yeast phosphatidylserine synthase in vivo and in vitro by cyclic AMPdependent protein kinase. Proc Natl Acad Sci US A 85, 7962-7966. Klein, C. \& Struhl, K. (1994). Protein kinase A mediates growthregulated expression of yeast ribosomal protein genes by modulating RAP1 transcriptional activity. Mol Cell Biol 14, 1920-1928.

Lewis, J. G., Northcott, C. J., Learmonth, R. P., Attfield, P. V. \& Watson, K. (1993). The need for consistent nomenclature and assessment of growth phases in diauxic cultures of Saccharomyces cerevisiae. J Gen Microbiol 139, 835-839.

Marchler, G., Schuller, C., Adam, G. \& Ruis, H. (1993). A Saccharomyces cerevisiae UAS element controlled by protein kinase A activates transcription in response to a variety of stress conditions. EMBO J 12, 1997-2003.

Matsumoto, K., Uno, I. \& Ishikawa, T. (1985). Genetic analysis of the role of the cAMP in yeast. Yeast 1, 15-24.

Russel, M., Bradshaw-Rouse, J., Markwardt, D. \& Heideman, W. (1993). Changes in gene expression in the Ras/adenylate cyclase system of $S$. cerevisiae: correlation with cAMP levels and growth. Mol Biol Cell 4, 757-765.

Tanaka, K., Matsumoto, K. \& Toh-e, A. (1988). Dual regulation of the expression of the polyubiquitin gene by cAMP and heat shock in yeast. $E M B O J \mathbf{7}, 495-502$.

Tatchell, K. (1993). $\mathrm{R} A S$ genes in the budding yeast Saccharomyces cerevisiae. In Signal Transduction. Prokaryotic and Simple Eucaryotic Systems, pp. 147-188. Edited by J. Kurjan \& B. L. Taylor. San Diego: Academic Press.

Thevelein, J. M. (1984). Regulation of trehalose mobilization in fungi. Microbiol Rev 48, 42-59.

Thevelein, J. M. (1994). Signal transduction in yeast. Yeast 10, 1753-1790.

Toda, T., Uno, I., Ishikawa, T., Powers, S., Kataoka, T., Broek, D., Cameron, S., Broach, J., Matsumoto, K. \& Wigler, M. (1985). In 
yeast, Ras proteins are controlling elements of adenylate cyclase. Cell 40, 27-36.

Toda, T., Cameron, S., Sass, P., Zoller, M. \& Wigler, M. (1987). Three different genes in S. cerevisiae encode the catalytic subunits of the cAMP-dependent protein kinase. Cell 50, 277-287.

Tokiwa, G., Tyers, M., Volpe, T. \& Futcher, B. (1994). Inhibition of G1 cyclin activity by the Ras/cAMP pathway in yeast. Nature 371, 342-345.

Van Aelst, L., Boy-Marcotte, E., Camonis, J. H., Thevelein, J. M. \& Jacquet, M. (1990). The C-terminal part of the CDC25 gene product plays a key role for signal transduction in the glucoseinduced modulation of the cAMP level in Saccharomyces cerevisiae. Eur J Biochem 193, 675-680.
Van Der Plaat, J. B. (1974). Cyclic 3',5'-adenosine monophosphate stimulates trehalose degradation in bakers' yeast. Biochem Biophys Res Commun 56, 580-587.

Watson, C. D. \& Berry, D. R. (1977). Fluctuations in cAMP levels during the cell cycle of Saccharomyces cerevisiae. FEMS Microbiol Lett 1, 175-178.

Wilson, R. R, Renault, G., Jacquet, M. \& Tatchell, K. (1993). The pde 2 gene of Saccbaromyces cerevisiae is allelic to rca1 and encodes a phosphodiesterase which protects the cell from extracellular cAMP. FEBS Lett 325, 191-195.

Received 23 June 1995; revised 17 October 1995; accepted 1 November 1995. 